\title{
Docência on-line compulsória: reflexões sobre a docência em tempos de isolamento social por força da pandemia da Covid-19
}

\author{
Silvar Ferreira Ribeiro ${ }^{1}$ \\ Sônia Maria da Conceição Pinto² \\ Aliana Alves de Souza ${ }^{3}$ \\ Leonardo Machado Nascimento ${ }^{4}$ \\ Marcia Margarida Nunes da Silva Martins ${ }^{5}$
}

\section{RESUMO}

O estudo foi realizado a partir das experiências da docência on-line e, sobretudo, dos desafios do modelo de Ensino Remoto, adotado sumária e compulsoriamente em vista das medidas legais de isolamento social exigidas durante a pandemia. Este artigo traz como problema as implicações pessoais e laborais percebidas por professores e estudantes no enfrentamento das novas condições de vida no decorrer da pandemia, incluindo-se as reflexões sobre as possibilidades de mudanças após esse período. Com a abordagem da pesquisa e inovação responsáveis e a utilização da metodologia de pesquisa-ação participativa, os autores imergiram no próprio objeto de estudo como sujeitos, submetidos a realizar o trabalho de forma remota, usando ferramentas tecnológicas. Os resultados mostraram os avanços que tal experiência proporcionou, bem como os desafios, as possibilidades e os caminhos no retorno pós-pandemia, pois as aprendizagens do Ensino Remoto permitirão inovar práticas docentes.

Palavras-chave: Educação. Rede. Pesquisa e inovação responsáveis RRI.

\footnotetext{
${ }^{1}$ sfribeiro@uneb.br - Universidade do Estado da Bahia

2 spinto@unbe.br - Universidade do Estado da Bahia

3 alasouza@uneb.br - Universidade do Estado da Bahia

4 Imnascimento@uneb.br - Universidade do Estado da Bahia

${ }^{5}$ mmmartins@uneb.br - Universidade do Estado da Bahia
} 


\section{Compulsory Online Teaching: reflections on teaching in times of social isolation by the Covid-19 pandemic}

\section{ABSTRACT}

The study was carried out based on the experiences of online teaching, especially the challenges of the remote teaching model, which was adopted summarily and compulsorily, in view of the legal measures of social isolation required by the pandemic. It brings as a problem: what are the personal and work implications perceived by teachers and students in the process of coping with the new living and working conditions during the pandemic, including reflections on the possibilities of changes that will come when its consequences are toned down? With the responsible research and innovation approach and participatory action research methodology, the authors immersed themselves in the object of study itself, positioning themselves as subjects, compelled to carry out the work remotely, using technological tools. The results show the advances that this experience provided us, the challenges, possibilities and paths, pointing to a return in the post-pandemic that allows us to innovate our practices with the learning of remote education.

Keywords: Education. Network. Responsible. Research and Innovation RRI. 
Os autores e autoras desta pesquisa são também os sujeitos da pesquisa, pois contribuímos com reflexões sobre a nossa própria prática docente e participamos da busca pelas fundamentações teóricas que sustentaram as análises. Somos 5 docentes - 3 professoras e 2 professores - da Universidade do Estado da Bahia (Uneb), lotados no Departamento de Ciências Humanas e Tecnologias (DCHT XIX), Campus XIX, que está localizado no município de Camaçari a 48 quilômetros da capital Salvador. Vivenciamos uma experiência inédita para nós, mas não exclusiva, uma vez que os demais integrantes da comunidade acadêmica passaram pela mesma situação de isolamento social, decorrente das medidas adotadas pelos governos para proteger as suas populações do contágio com o vírus da Covid-19. A pandemia, que, segundo as autoridades sanitárias, teve início no final de 2019, estende-se até os dias atuais - outubro de 2021 -, momento em que foi produzido este texto.

Pode-se afirmar que foram vivenciadas mudanças profundas nas nossas vidas pessoais e profissionais para enfrentar e superar as agruras desta catástrofe mundial, que teve como marco inicial o dia 11 de março de 2020, quando a Organização Mundial da Saúde (OMS) declarou que o mundo entrou em estado de pandemia, pouco mais de 3 meses depois de constatado o primeiro caso da infecção na cidade de Wuhan na China.

Uma pandemia, de acordo com Vick (2021), é a disseminação mundial de uma nova doença, para a qual a humanidade não tem defesas, e, muitas vezes, não há uma substância conhecida que possa combatê-la. O mesmo autor afirma ainda que a propagação da doença em uma pandemia acontece de forma inesperada, e, comumente, descontrolada, cruzando fronteiras e atingindo uma grande parte da população ao mesmo tempo. Os agentes transmissores do Coronavírus, causador da Covid-19, são as pessoas de todas os matizes étnicas, classe social, idade etc., e a transmissão é potencializada pela intensa circulação, numa economia transnacionalizada pelo turismo, pelas viagens de negócios - viabilizadas pelo intenso tráfego aéreo, terrestre e marítimo - por meio de transportes modernos, que encurtam a distância e o tempo de deslocamento.

Enquanto escrevíamos este artigo, o mundo já registrava mais de 232.636 .622 casos de infecção confirmados e mais de 4.762 .089 mortes, sendo o número de casos diários de 407.664 novas infecções ao redor do mundo, segundo dados do site oficial da Organização Mundial da Saúde (OMS). No Brasil, segundo a mesma fonte, contabilizavam-se 594.653 mortes acumuladas e aproximadamente 21.366 .395 casos confirmados da doença, além de 14.423 novos casos diários. Após um ano e meio de decretada a pandemia, o Brasil encontra-se em segundo lugar no ranking mundial de casos da doença, perdendo apenas para os Estados Unidos, que apresenta um acumulado de 695.114 mortes, com 4.349.211 casos confirmados da doença.

Todo esse cenário desolador, entretanto, vem sendo atenuado pela esperança de que a fase mais difícil já esteja superada, uma vez que a ciência deu uma resposta muito rápida, produzindo vacinas que foram amplamente aplicadas nas populações, o que sinalizou uma possibilidade concreta de superação da doença. Apesar disso, é indispensável registrar que o risco ainda não está afastado, principalmente em virtude das profundas desigualdades sociais 
em todo o mundo, fato que tem levado os países mais pobres, assim como os segmentos menos favorecidos das populações, a não terem acesso à vacina, bem como ao tratamento da doença. Por isso, o nível de alerta se mantém até agora elevado, pois há os perigos das novas variantes do vírus que podem trazer de volta as ameaças.

Diante dessa emergência global, o Governo do Estado da Bahia publicou em diário oficial, no dia 16 de março de 2020, o decreto n. ${ }^{\circ} 19.529$ - ainda em vigor nos dias de hoje -, que regulamentou medidas temporárias para o enfrentamento da emergência de saúde pública decorrente do coronavírus, determinando o isolamento social, a quarentena e um conjunto de outras medidas, com a finalidade de conter a transmissão da doença em larga escala (BAHIA, 2020).

Nesse período, surgiu a necessidade do chamado home office, pois, fechadas em suas casas e impedidas de realizarem as atividades da sua vida diária - tais como, ir à escola, à universidade, ao trabalho e aos locais públicos, onde exerciam as suas atividades de lazer, esporte e interações sociais das mais diversas - as pessoas, passado o impacto inicial, passaram, segundo Almeida, Almeida e Silva (2020), a buscar novas formas de relacionamento, de trabalho e de estudos, reinventando hábitos e buscando de forma rápida dar respostas inteligentes às incertezas do momento.

Nesse contexto, surgiu o interesse e a necessidade de fazer esta pesquisa. A motivação principal foi encontrar a resposta para a pergunta que nos fizemos desde o início: quais as implicações pessoais e laborais percebidas por professores e estudantes no processo de enfrentamento das novas condições de vida e de trabalho durante a pandemia, incluindo-se as reflexões sobre as possibilidades de mudanças que virão quando as suas consequências estiverem atenuadas?

A metodologia utilizada neste estudo foi a da pesquisa-ação participativa, pois, imersos no próprio objeto de estudo, os pesquisadores-sujeitos - docentes que se viram impelidos a realizar o seu trabalho de forma remota, usando tecnologias da informação e comunicação destinadas às interações síncronas e assíncronas - experimentaram essa nova realidade e refletiram sobre ela, registrando suas impressões e sentimentos, compartilhando entre si os registros, debatendo-os e buscando interpretá-los para gerar significados, compreensões, respostas e novas perguntas. Isso veio a contribuir para o enfretamento das dificuldades do momento, bem como para a preparação do ainda desconhecido momento futuro, no pós-pandemia, levantando hipóteses e proposições para alimentar o debate sobre o já iminente retorno para uma realidade ainda desconhecida e desafiadora.

A abordagem RRI, do inglês Responsible, Research and Innovation, traduzidos livremente como pesquisa e inovação responsáveis, também foi usada como base de referência do presente estudo. Tal método preconiza um conjunto de princípios adotados como balizadores do processo de produção e de análises dos dados; os princípios são da educação científica, da ciência aberta, da igualdade de gênero, da ética da governança e do engajamento público, cada um deles trazidos para o bojo das discussões e das análises aqui produzidas. 
Atendendo ao citado decreto do governo estadual que determinou o fechamento das atividades presenciais no dia 16 de março de 2020, o Conselho Superior (CONSU) da Universidade do Estado da Bahia publicou a resolução n. ${ }^{\circ}$ 1.406/2020, de 19 de março de 2020 (UNEB, 2020), regulamentando um plano de ação para o enfrentamento da pandemia no âmbito da Uneb. $A$ suspensão motivou a paralização das atividades em toda a universidade.

No Departamento de Ciências Humanas e Tecnologias (DCHT XIX) da Universidade do Estado da Bahia, após os primeiros 45 dias decorridos da paralização das atividades acadêmicas, houve uma mobilização da comunidade acadêmica em busca de alguma alternativa para não perder os vínculos com as suas atividades, projetos, aspirações e relações entre os seus membros.

Foi criado pelo Conselho Departamental um Grupo de Trabalho Interdisciplinar (GT Inter) composto por estudantes, servidores técnico-administrativos e professores dos cursos de Bacharelado em Ciências Contábeis e Direito, por meio de ato administrativo interno, com o objetivo de "discutir e apresentar propostas para a utilização de tecnologias on-line nas atividades acadêmicas durante a pandemia da Covid-19, no âmbito do Campus XIX". Os trabalhos do GT Inter foram realizados de forma remota, com reuniões semanais. Foram criadas duas comissões temáticas - uma pedagógica e outra tecnológica - que fizeram reuniões específicas sobre suas áreas para trazer ideias e sugestões a serem debatidas no GT, nas reuniões gerais.

Os resultados dos trabalhos do GT Interdisciplinar forneceram ao DCHT XIX e seus respectivos colegiados de Ciências Contábeis e Direito subsídios para planejar e realizar as atividades complementares, visando viabilizar as atividades acadêmica durante o período de isolamento social. Além disso, tal implementação possibilitou o estudo de soluções pedagógicas e tecnológicas que serviram de base paras as etapas seguintes. As atividades das comissões, bem como os resultados de estudos e discussões deram subsídios para a realização do I Seminário Interdisciplinar On-line do DCHT XIX e também motivaram a criação de projetos de Comunidades On-line de Aprendizagem, que se encontram em funcionamento até os dias atuais.

Dando prosseguimento à apresentação das vivências do período de isolamento social com suspensão das atividades presenciais, o mês de novembro de 2020 marcou a retomada das aulas de forma remota através da oferta de um semestre letivo especial, denominado Período Extraordinário de Oferta (PEO) - entre os dias 09 de novembro e 30 de dezembro de 2020 -, regulamentado pela Resolução n. ${ }^{\circ}$ 2.082/2020, do Conselho Superior de Ensino, Pesquisa e Extensão (CONSEPE), como proposta de viabilização das atividades de Ensino de Graduação de forma gradual e facultativa em decorrência do distanciamento social decretado para evitar o contágio pelo novo Coronavírus. O PEO foi descrito pela resolução que o instituiu como,

O Plano Extraordinário de Oferta de Componentes Curriculares e demais atividades acadêmicas para o Ensino de Graduação é uma proposta pedagógica emergencial para a realização de atividades não presenciais em situação de distanciamento social determinado pelas autoridades de saúde pública (UNEB, 2020, p. 39).

A oferta especial foi marcada por muitas novidades e flexibilizações das normas acadêmicas, uma vez que seu principal objetivo, para além de fazer uma tentativa de retomada 
das aulas em meio remoto, foi de funcionar como um período experimental e preparatório. Por esse motivo, a adesão por parte de estudantes e até de professores foi voluntária, tendo em vista o respeito pelas condições adversas que muitos se encontravam, tais como: as dificuldades de acesso às tecnologias e à internet; as situações de saúde, o acometimento com a doença provocada pelo vírus - seja do professor, do estudante, dos técnicos, do pessoal de apoio, ou mesmo de familiares; questões de natureza econômica, isto é, desemprego e falta de meios de subsistência - fatos estes relatados em alguns casos; além de outras questões. O PEO permitiu ainda que, mesmo matriculados voluntariamente, aqueles que não frequentassem ou não obtivessem êxito na aprovação das disciplinas que se matricularam, não seriam penalizados com registros de reprovação, tendo sido autorizada a exclusão desses componentes curriculares do histórico acadêmico dos estudantes.

Nesse período de oferta extraordinária, instituiu-se a codocência, modalidade de atuação em que professores puderam compartilhar em duplas a oferta da mesma disciplina, visando a conjugação de esforços e a troca de experiências, além da complementaridade de habilidades e competências entre docentes para viabilizar o enfrentamento às dificuldades inerentes ao desafio das aulas remotas.

Passado o PEO 2020, veio a primeira oferta de um semestre integral em regime remoto, com o início das aulas para o semestre letivo de 2021.1, no dia 01 de março de 2021 e encerramento no dia 09 de julho de 2021. Dessa vez, apesar de mantidas as condições especiais do Ensino Remoto, pois os Departamentos permaneceram fechados em virtude da pandemia, tivemos um semestre com calendário integral, de 101 dias letivos. Mais uma vez, o CONSEPE editou normas que orientaram a comunidade acadêmica sobre os procedimentos para o Ensino Remoto, recomendando cuidados com a duração das aulas, permitindo-se a redução e carga horária online síncrona. Essas normas também sugeriram aos professores a adoção de atividades assíncronas, o uso de ambientes virtuais de aprendizagem para realizar as orientações acadêmicas, a capacitação de todos para o acesso às plataformas digitais - lançando programas de apoio para a aquisição de equipamentos e fornecendo chips de dados móveis -, tudo para permitir àqueles impossibilitados de adquirir esses recursos o direito de participar das aulas.

\section{BASES CONCEITUAIS}

Na tentativa de compreensão de todo esse processo vivido com a suspensão das atividades acadêmicas e o retorno, passando por etapas de retomada gradual, pesquisamos por autores que já vinham estudando os processos de aprendizagem e a sua relação com as Tecnologias Digitais de Informação e Comunicação (TDIC). Buscamos, inicialmente, compreender o contexto social em que vivíamos e a sua relação com os processos de aprendizagem. Pozo (2008, p. 25) afirma que "cada sociedade, cada cultura gera suas próprias formas de aprendizagem, sua cultura da aprendizagem". Assim, é em função da aprendizagem que adquirimos a cultura, esta que está totalmente incorporada a novas formas de aprendizagem. Nesse sentido, deparamo-nos com o desafio de nos apropriarmos desse novo momento cultural vivenciado com o isolamento social e, ao mesmo tempo, de identificarmos ou desenvolvermos novas formas de aprendizagem, que nos ajudassem a ampliar as nossas experiências, como professores ou estudantes. 
Tomando como base as reflexões do autor supracitado, discutimos essa nova cultura de aprendizagem e aqui acrescentamos de "ensinagem", pois entendemos, tal como o autor, que há necessidade da aprendizagem dessa cultura para ambos os lados, tanto do professor quanto do aluno. Pozo (2008, p. 48) nos diz que,

a) cada sociedade, cada cultura cria suas próprias formas de aprendizagem, sua cultura da aprendizagem;

b) as atividades de aprendizagem precisam ser entendidas no contexto das demandas sociais que as geram;

c) a função basilar da sociedade humana é incorporar a cultura, para que faça parte dela;

d) a necessidade de aprendermos uma nova cultura de aprendizagem que atenda os processos de formação e educação da sociedade atual demanda identificarmos quais são esses novos processos para nos posicionarmos criticamente;

e) a sociedade atual nos impõe, continuamente, novas aprendizagens, que demandam dos professores e alunos uma relativização de conhecimentos que vai além da simples reprodução deles.

Observemos que, ao escrever o texto acima, ainda não estávamos vivendo a pandemia, entretanto, as reflexões trazidas pelo autor nos remetem imediatamente a pensarmos nas implicações desse processo em relação à aprendizagem e ao ensino. Vejamos que, mesmo não fazendo parte da cultura da nossa sociedade, as demandas do Ensino Remoto, imposto pelas medidas de isolamento social, nos impele a criar culturas de aprendizagem, de incorporá-las, de nos posicionarmos criticamente diante delas e de pensarmos também sobre essa grande constatação da necessidade de relativizar os conhecimentos, indo além da simples reprodução.

Verificamos também a urgência de trazermos conceitos como o de "educação convergente" de Belloni (2015), que já dizia que a educação no futuro é a convergência de dois grandes paradigmas da educação de nosso século: o ensino convencional presencial e a educação aberta a distância. Isso possibilitará minimizar as diferenças metodológicas entre eles criando modelos, nos quais metodologias e técnicas não presenciais serão cada vez mais utilizadas pelo ensino convencional, ao passo que as instituições especializadas em Educação a Distância (EaD) tenderão a adotar atividades presenciais para abranger em seus cursos aquelas carreiras que exigem esse tipo de atividade.

Da mesma forma, evocamos Libâneo (2000) que, refletindo sobre a educação mediada pelas tecnologias digitais, nos falava que a educação é o conjunto das ações, processos, influências e estruturas que intervêm no desenvolvimento humano de indivíduos e grupos, na sua relação ativa com o meio natural e social, num determinado contexto de relações entre grupos e classes sociais.

Trazemos também o conceito da interdisciplinaridade, que emergiu com muita força neste período quando fomos instad os a compartilhar as nossas classes e juntar os nossos esforços para atuar na emergência dos tempos pandêmicos. Sobre tal conceito, Pierson e Neves (2013) dizem que para que ocorra a transição de um fazer pedagógico isolado para um trabalho intensamente 
integrado é imprescindível que os envolvidos estejam abertos ao diálogo, à integração e ao constante cambio de seus conhecimentos especializados ampliando a quantidade e a qualidade de suas colaborações.

Com o intuito de finalizar o conjunto de conceitos e reflexões teóricas, trabalhamos com a ideia da literacia digital, necessária para que todos os envolvidos nas demandas da educação remota possam ampliar as suas habilidades e lidar com os recursos tecnológicos, uma vez que, sem a escolha de atuar por meios tradicionais propiciados pela presencialidade, fomos todos compelidos a interagir com as TDIC, única alternativa disponível para realizarmos o nosso trabalho docente e, no caso dos alunos, para participarem das aulas.

\section{METODOLOGIA}

São duas referências metodológicas que orientam as bases científicas desta pesquisa. A primeira é a abordagem da pesquisa e inovação responsáveis (RRI), sendo esta uma base epistemológica, visto que se apresenta como uma concepção de pesquisa. Assim, fundamentados nos conceitos da RRI, atendemos a cada um dos seus pilares, começando pelo ético, por meio de uma pesquisa autodirigida, em que todos os participantes são coautores e ao mesmo tempo sujeitos.

Aqui não precisaremos de autorização para uso de dados, considerando que estamos lidando todos e todas na condição de autores das nossas próprias reflexões e assinamos o artigo sem a utilização de dados de terceiros. No pilar da governança, que se refere à economicidade, a sustentabilidade do processo de pesquisar, observamos que não foram empregados recursos financeiros ou materiais de terceiros, senão os próprios já investidos pelo Estado para a nossa manutenção, visto que que somos servidores públicos, professores da universidade e temos como obrigação funcional, ensinar, fazer pesquisa e extensão. Ao elaborarmos essa pesquisa e publicarmos seus resultados, estamos cumprindo, portanto, o nosso papel social e contribuindo para que a universidade supere as dificuldades impostas pela pandemia a partir das nossas conclusões.

Outro pilar da RRI, a igualdade de gênero, foi amplamente atendido: dos cinco autores três são do sexo feminino e dois do masculino. No pilar engajamento público - que define o envolvimento dos sujeitos da pesquisa em todas as suas etapas -, asseguramos que todas as diretrizes e decisões tomadas nesta pesquisa contaram com a participação ativa dos seus integrantes, sendo o estudo realizado com os sujeitos e não para eles.

Por fim, restam a ciência aberta, que orienta a transparência e disponibilização dos dados da pesquisa para a sociedade, atendida nesta publicação, pois tornou os dados acessíveis a todos, colocando os pesquisadores e pesquisadoras, ao disponibilizarem seus contatos, à disposição para o debate, a reflexão e fornecimento dos registros da pesquisa para qualquer interessado; e a educação científica, um dos pilares mais importantes, assegurado pelo compartilhamento dos caminhos metodológicos e dos registros de dados de forma aberta para os participantes.

A segunda referência metodológica foi o método da pesquisa-ação participativa, adotado pelas características do estudo, marcado por um movimento de reflexão-ação-reflexão, que 
acompanhou todo o processo de concepção e implementação do projeto, assim como as etapas de análise, de escrita e de publicação dos resultados.

Os procedimentos metodológicos que resultaram na produção dos dados foram: as reuniões entre os participantes; os registros através de áudios e de textos colaborativos; as discussões de ideias e de princípios teóricos adotados; o compartilhamento de textos e troca de experiências no decorrer de cada uma das etapas, desde o I Seminário Interdisciplinar On-line, etapa que demarcou o início do processo, perpassando pelos períodos do semestre extraordinário (PEO) e do semestre especial 2021.1.

Seguiram-se as análises e a produção dos textos para a publicação dos resultados, apresentados na próxima seção.

\section{VIVÊNCIAS E REFLEXÕES}

Neste grupo de pesquisadores, temos perfis bem diferenciados, e a escolha dos membros teve a intencionalidade de juntar ao processo professores sem familiaridade com o uso das tecnologias para as suas atividades de ensino, pesquisa e extensão, atuando com professores versados no tema, especialistas e pesquisadores da área.

Sem identificar os participantes, trouxemos aqui depoimentos e análises que vão contribuir para a compreensão do processo, visando a busca das respostas à nossa indagação inicial. Os depoimentos e debates mostraram que as percepções iniciais, assim como as ocorridas durante o processo, vão do temor, do descrédito à constatação de barreiras, de dificuldades, evoluindo para situações de superação e descobertas.

O primeiro registro obtido, leva a questão da pandemia para uma dimensão que vai muito além das questões acadêmico-laborais, na medida em que o participante da pesquisa afirma

Desde do início do surgimento aqui na Bahia dos primeiros casos da Covid-19, provocada pelo Coronavírus, que motivou a decretação, pelo governo do Estado, em março de 2020, do isolamento social com a suspensão, dentre outras, das atividades acadêmicas, temos vivido momentos de muita angústia, medo, incertezas e desafios em busca de alternativas capazes de enfrentar esses momentos tão difíceis, que muito tem nos impactado cotidianamente para prosseguir com nossa trajetória profissional, familiar e social (sujeitoa/autor-a N/I).

Observe-se que se fala de angústia, medo, incertezas e desafios para prosseguir a vida nos campos profissional, familiar e social. Esses são sentimentos que extrapolam as nossas possibilidades de uma análise mais profunda, tendo em vista que adentram para além das questões acadêmicas, que poderiam ensejar um trabalho profissional da área da psicologia, levando-nos a registrá-lo para efeito de ampliação do alcance das constatações da pesquisa, mas remetendo-o para outras possibilidades de serem tratados no âmbito da universidade com a ajuda do seu setor de saúde.

Outro trecho de falas abordadas pelo grupo, traz uma perspectiva laboral e afunilam a percepção nas questões acadêmicas quando observamos o que foi dito: 
[...] meu sentimento era de impotência e muitas dúvidas em relação ao futuro próximo das minhas atividades, já que o isolamento social era uma realidade, $\mathrm{e}$ nossas experiências das práticas docentes sempre foram realizadas de forma presencial, e esse momento presente exigia uma nova concepção do fazer pedagógico, num formato de ambiente virtual (on-line), através das plataformas digitais (sujeito-a/autor-a N/I).

Vê-se aqui um sentimento de incerteza em relação ao futuro, uma vez que as práticas que levavam a uma sensação de segurança deveriam ser forçosamente substituídas pelo desconhecido. Acrescentando-se outro depoimento a este, afirma o participante do estudo, num ato espontâneo, o seu ceticismo e desconfiança em relação à alternativa proposta para dar prosseguimento às aulas:

Confesso que num primeiro momento em que nosso Departamento buscou construir uma agenda para viabilizar o retorno das nossas atividades acadêmicas no modelo on-line, muito em razão da visão preconceituosa, por nunca ter experimentado e atuado nessa modalidade de prática pedagógica em ambiente virtual e por desconhecer as ferramentas utilizadas nesse modelo de ensino, sempre fui muito cético quanto à funcionalidade dessa modalidade que, para mim, sempre soava como um modelo que criava facilidades para oportunizar o alunado que negligenciava seu interesse pelos seus estudos, e que, neste sentido, para mim era uma situação extremamente desconfortável por não confiar nesse tipo de prática, embora entendendo que o momento exigia providências urgentes para enfrentar essa situação que em verdade afetava em boa medida a todos nós da comunidade acadêmica, com reflexo no ambiente familiar e social em função do isolamento social posto em prática (sujeito-a/autor-a N/I).

Observamos aqui uma razão muito forte para o indivíduo não aceitar a nova realidade, numa confissão de preconceito, de desconfiança, de desconhecimento, de desconforto. $O$ debate franco no grupo e a abertura para experimentar, ainda que em virtude das circunstâncias, criou a oportunidade de praticar e de tentar compreender. Observamos no depoimento uma motivação muito forte quando o participante registra que "o momento exigia providências urgentes".

A abertura para experimentar, motivada por um evidente senso de responsabilidade, por outro lado, permitiu outras constatações, o que possibilitou colher depoimentos como:

Se por um lado, num primeiro momento, o isolamento social por conta da Covid-19 provocou (e de certa forma continua provocando) medo, angústia e incertezas, inclusive nos trazendo em alguma medida afetações emocionais, por certo que também tem nos deixado esse imenso legado de riqueza de aprendizado, permitindo nos reinventarmos na prática docente e nos estimulando a ir mais adiante em busca de novos e desafiadores caminhos de conhecimento para superar esses obstáculos, para atuar de forma satisfatória no exercício do ensino aprendizado com o uso de tecnologias em ambientes virtuais, através das plataformas digitais, que muito tem nos ajudado a interagir com nossos alunos de forma mais segura, confiante e tranquila, sabendo e reconhecendo que, embora essa modalidade de ensino tenha avançado no âmbito das práticas de ensino aprendizado, entendemos que esse formato, por ouro lado, não é um modelo excludente da prática pedagógica presencial, que 
na minha percepção ainda continua sendo imprescindível e fundamental para o fazer pedagógico (sujeito-a/autor-a N/I).

No mesmo registro de dados em que nos deparamos com vários sentimentos de não aceitação dessa nova realidade, encontramos afirmações como estas acima, que denotam uma mudança substantiva da forma de perceber e de reagir aos desafios postos. Aqui percebemos a mudança de cultura de aprendizagem apresentada por Bozo (2018), a emergência de uma educação convergente aludida por Belloni (2000), a importância das tecnologias digitais da informação e comunicação trazida por Libâneo (2000).

Ao seguirmos nas análises, encontramos outros elementos que são relevantes para este estudo. 0 participante da pesquisa, que também fez alusões a momentos de dificuldades e incertezas, apresenta em seguida um depoimento em que nos diz:

Partindo de todas as transformações vivenciadas ao longo destes aproximados 20 meses em que vivemos as atividades remotas na Universidade, o que posso acrescer a tudo que já foi dito quando da produção do nosso primeiro material, é que temos vivido uma verdadeira revolução cultural. Nos meus estudos de ações culturais, os movimentos sociais, jamais imaginei que poderia introduzir essas mesmas ações nas disciplinas técnicas do direito, como as fiz em Direito e Processual Penal e Prática Jurídica (sujeito-a/autor-a N/I).

Vemos um relato que tem elementos de dúvidas, mas evidentes sinais de satisfação e surpresa. Fazer coisas antes inimagináveis certamente foi uma das constatações frequentes neste estudo. $O$ indivíduo que fez esta constatação tem o seu pensamento complementado quando analisamos esta fala:

Posso dizer tranquilamente que passei de Docente para Produtora Cultural, pois a cada dia tento inventar uma nova forma de atrair e manter os alunos presentes. As descobertas das novas pedagogias, além de transmitir conhecimentos, passam a nos preocupar em descobrir novas ferramentas para auxiliar nesse momento desafiador (sujeito-a/autor-a N/I).

Essa descoberta de si como protagonista de outros atos de cultura e de apropriação de novas competências e habilidades, ao mesmo tempo que encorajam, ampliam horizontes e perspectivas de atuação, surgidas das dúvidas e das incertezas. Se por um lado, vista no conjunto das falas soa como uma estratégia de sobrevivência, por outro revela uma motivação que se assemelha a uma conquista desejada, sem que antes tivesse sido, sequer, imaginada.

Apesar de não trazermos depoimentos de estudantes, muitos, espontaneamente, enviaram elogios e manifestações de surpresa com a quantidade de aprendizados e de crescimento, pois não esperavam tal resultado quando foram chamados para participarem do Ensino Remoto.

Seguindo nesta análise da situação dos estudantes, muitas questões foram levantadas no grupo sobre a situação vivida por eles. Preocupações com a situação de vida de cada um, com a distância que percorriam para se dirigirem até o campus, com as suas, muitas vezes, precárias condições de vida, visto que são oriundos de famílias de baixa renda e residem em condições 
desfavoráveis para enfrentarem o desafio do Ensino Remoto, bem como para se prepararem para o retorno às aulas.

Foram feitas referências e discussões sobre os aspectos mais amplos do processo de enfrentamento do isolamento social, inclusive enfatizando-se, dentre outras mudanças, a matrícula interdepartamental, que permitiu a interação entre estudantes de diversos campi, de cidades diferentes, destacando-se aqui a riqueza das experiências vividas neste contexto da abertura para a troca de experiências que se tornaram possíveis. Verificamos também uma certa ansiedade, por parte dos estudantes, pelo retorno às aulas, o que pode ser apontado como um aspecto positivo do Ensino Remoto.

Destacou-se ainda a inegável possibilidade criada para a cooperação entre os professores e os alunos, tendo em vista que muitos dos estudantes matriculados eram jovens, muitos deles com vivências no uso das tecnologias, foram de grande importância para ajudar os professores, especialmente aqueles que foram obrigados a aprender no processo, pois não se utilizavam dos recursos tecnológicos de forma intensiva antes desse período, o que proporcionou um ambiente de trocas e de crescimento mútuo.

Importante salientar também que no momento inicial das discussões no âmbito dos Grupos de Trabalho, tecnológico e pedagógico, criados para viabilizar a elaboração das propostas de retomada das atividades acadêmicas no modelo on-line, uma das principais preocupações era justamente trazer uma proposta de atividade que atendesse aos princípios fundamentais, os quais sempre nortearam e marcaram a história da trajetória dos trinta anos de existência da Universidade do Estado da Bahia (Uneb), como uma instituição inclusiva e acolhedora, expressa nas suas várias dimensões, forjado na expressão viral de resistência "ninguém solta a mão de ninguém" (Bispo, 2019).

Nesse sentido, a participação de todos os alunos, considerando suas especificidades, já que parte significativa dos estudantes da Uneb e do nosso Departamento possuem um perfil de vulnerabilidade socioeconômica e material pela falta de condições para adquirir equipamentos e estrutura de comunicação - computadores, tablets, smartphones e acesso às redes de internet - condizentes com as necessidades específicas dessa prática pedagógica de acesso às plataforma digitais no modelo on-line, o que poderia dificultar e certamente comprometer sua efetiva participação nas atividades propostas nesse modelo.

Dos momentos mais críticos e sensíveis no processo de execução das atividades acadêmicas nesse modelo on-line e que tocou profundamente foi constatar o que já se percebia no formato presencial, porém agora, neste momento de isolamento social, de forma mais explícita e contundente, observada e muitas vezes relatadas no curso da nossa prática pedagógica, em relação às dificuldades socioeconômicas e materiais de muitos desses alunos. Essa realidade tem nos levado a refletir mais profundamente sobre essas questões, com o intuito de buscar alternativas institucionais que possam mitigar esses obstáculos.

Contudo, em que pese tal constatação, não poderia deixar de ser registrado e observado, com muita satisfação, o elevado nível de consciência, compromisso, entrega, obstinação e, sobretudo, a grande capacidade de superação desses alunos no enfrentamento desses desafios, que muito nos ajudou e tem ajudado na construção dessa caminhada das práticas pedagógicas no sistema on-line e que também nos motiva a seguir adiante. 


\section{CONSIDERAÇÕES FINAIS}

A título de vislumbrarmos respostas para a complexa questão que levantamos neste estudo, que versava sobre as implicações pessoais e laborais percebidas por professores e estudantes no processo de enfrentamento das novas condições de vida e de trabalho durante a pandemia, constatamos nos registros e análises apresentados, que as ricas percepções, as surpreendentes descobertas, os avanços na aprendizagem e nas formas de ensinar, as trocas culturais, as constatações que desafiaram preconceitos, as descrenças, os medos, as angústias, assim como a ampliação das formas de compreender as relações entre os sujeitos que integram uma comunidade acadêmica, foram reveladores no presente, levando-nos a refletir sobre o passado e abrindo-nos perspectivas para pensarmos o futuro.

Neste momento, estamos debatendo na universidade a tão esperada volta às salas de aula no formato presencial, entretanto, percebemos - e isso já é a preocupação que trazemos como base para a continuidade desta pesquisa - que essa volta, muito provavelmente, não será um retorno para a mesma situação que nos encontrávamos em março de 2020.

O momento nos impõe reflexões mais amplas, e isso é o que já estamos fazendo ao debater o que está sendo chamado de Ensino Híbrido. Para alguns, essa modalidade se reduz a uma intepretação simplista do significado da palavra, dirigindo-se para um modelo de ensino que seria feito em parte presencial e parte on-line, a distância ou remoto. No entanto, as possibilidades que essa experiência nos desafiou a enfrentar, aponta para caminhos mais ricos e diversificados.

Perguntamos para encerrar - ou seria para começar? - se não poderíamos aproveitar todas as vantagens inegáveis do encontro presencial, que nos conforta com o calor humano da relação com o nosso semelhante, sem desprezar todas as vantagens que foram aqui apresentadas, propiciadas pelo uso das tecnologias digitais da informação e da comunicação, que tanto nos fizeram aprender e descobrir novas formas de exercermos a nossa missão humana e social como professores e professoras?

\section{REFERÊNCIAS}

ALMEIDA, F. J.; ALMEIDA, M. E.; SILVA, M. G. M. (orgs.). De Wuhan a Perdizes: Trajetos Educativos. São Paulo: EDUC, 2020.

BAHIA. Decreto n ${ }^{\circ} 19.529$ de 16 de março de 2020. Regulamenta, no Estado da Bahia, as medidas temporárias para enfrentamento da emergência de saúde pública de importância internacional decorrente do coronavírus. Diário Oficial do Estado da Bahia, n. 19529, 17 mar. 2020. Disponível em: http://www.legislabahia.ba.gov.br/documentos/decreto-no-19529-de-16-de-marco-de-2020. Acesso em: 08 dez. 2021.

BELLONI, M. L. Educação à distância. Campinas: Autores Associados, 2020.

BELLONI, M. L. Educação à distância. 7. ed. Campinas: Autores Associados, 2015. 
BISPO, T. (org.). Ninguém Solta a Mão de Ninguém: Manifesto Afetivo de Resistência e pelas Liberdades. Belo Horizonte: Claraboia, 2019.

LIBÂNEO, J. C. Pedagogia e pedagogos, para quê? 3. ed. São Paulo: Cortez, 2000.

PIERSON, A. H.C.; NEVES, M. R. Interdisciplinaridade na formação de professores de ciências: conhecendo obstáculos. Revista Brasileira de Pesquisa em Educação em Ciências, São Carlos, v. 1, n. 2, p. 120-131, 2013. Disponível em: https://periodicos.ufmg.br/index.php/rbpec/article/view/4168. Acesso em: 26 fev. 2021.

POZO. I. J. Aprendizes e Mestres: A nova cultura da aprendizagem. Porto Alegre: Artmed, 2008.

UNIVERSIDADE DO ESTADO DA BAHIA (UNEB). Resolução CONSU n. ${ }^{\circ}$ 1406/2020. Diário Oficial do Estado da Bahia, p. 39, 19 mar. 2020. Disponível em: https://portal.uneb.br/serint/wp-

content/uploads/sites/56/2020/03/1.406-consu-Res.-Plano-de-A\%C3\%A7\%C3\%A3o-UNEB-paraenfretamento-ao-COVID-19.pdf. Acesso em: 08 dez. 2021.

UNIVERSIDADE DO ESTADO DA BAHIA (UNEB). Resolução CONSU n. ${ }^{\circ} 2.082 / 2020$. Diário Oficial do Estado da Bahia, p.39, 23 out. 2020. Disponível em: https://portal.uneb.br/prograd/wpcontent/uploads/sites/63/2020/10/2082-consepe-Res.-Plano-de-Oferta-Extra.pdf. Acesso em: 08 dez. 2021.

VICK, M. Pandemia: origens e impactos, da peste bubônica à covid-19. 2021. Disponível em: https://www.nexojornal.com.br/explicado/2020/06/20/Pandemia-origens-e-impactos-dapestebub\%C3\%B4nica-\%C3\%A0-covid-19. Acesso em: 03 dez. 2020. 